\title{
Communicative Action, the Lifeworlds of Learning and the Dialogue that we Aren' $t^{1}$
}

\author{
Pádraig Hogan
}

\begin{abstract}
The first section of the paper reviews the kind of action which unfolds in Plato's Republic, and argues that, from Book II onwards, its character shifts from a genuine dialogue (communicative action) to a more manipulative kind of intercourse (strategic action). While the former kind of action was characteristic of the educational activities of the historical Socrates, the case is made that this kind of action became largely eclipsed in Western education and superseded by the strategic concerns to which Platonist conceptions of learning gave prominence. The Platonist legacy, it is pointed out, had a decisive impact on Western conceptions of learning, even beyond the Enlightenment. These conceptions were largely custodial rather than emancipatory in character. An argument is presented in thirteen steps in the second section of the paper, to establish the case that the kind of action which properly describes the experience of teaching and learning is that of a cultural courtship. A distinction is drawn between honourable and dishonourable forms of courtship, the honourable being a candidate for defence in universalist terms. The practical import of the distinction is considered. Under the title 'The Dialogue that we Aren't', the third section reviews postmodern objections - particularly those of Lyotard - to the kind of argument made in the thirteen steps, and the concluding section considers Habermas' later theories in relation to my own 'universalist' argument.
\end{abstract}

Key terms: communicative action; courtship; 'the dialogue that we are' (Gadamer); postmodernism; Plato's custodianship; virtues of teaching and learning

\section{Communicative and Strategic Action}

There is an intriguing tale in Plato's Republic which is often referred to as the 'noble lie', or alternatively as the 'magnificent myth'. In this tale, the rulers of the polis - but those alone - are envisaged by Plato as having the authority to use systematic falsehoods in dealing with the citizens, if it is for the greater good of the polis. ${ }^{2}$ Drawing on this authority, the rulers are to furnish the public's consciousness with the following account of the origins of human society:

International Journal of Philosophical Studies Vol. 4 (2), 252-272

(C) Routledge $1996 \quad 0967-2559$ 
You are, all of you, in this polis, brothers. But when god fashioned you, he added gold in the composition of those of you who are qualified to be rulers, (which is why the ruler's prestige is greatest); he put silver in the auxiliaries, and iron and bronze in the farmers and other workers. Now since you are all of the same stock, though your children will commonly resemble their parents, occasionally a silver child will be born of golden parents, or a golden child of silver parents, and so on. ${ }^{3}$

Plato charges the rulers with keeping a watchful eye on 'the mixture of metals' in the characters of the children, as the privileges of education and the powers of leadership are to be reserved for the most promising: the silver and especially the gold. A bronze child born to a family of high rank must be demoted to the ranks of industrial and farm workers, and similarly, a golden child born to a family of low rank must be promoted to receive the lengthy education which will equip him or her to be a ruler. The noble lie makes imperative the abolition of the family and domestic household and their replacement by mating festivals and state nurseries. The rulers are to see to it that during such festivals gold mates with gold as often as possible and bronze with bronze as seldom as possible. An ingenious lottery is to be contrived for this purpose so that those who are disappointed in their mate can 'blame the lot and not the Rulers'.

Now if we were to put this tale in Habermas' terms, Plato's noble lie looks like a comprehensive warrant for regarding the conduct of public life as an exercise in 'strategic action', as distinct from 'communicative action'. A state-controlled education system is to play the key part in enforcing this warrant, and it seems that the entire educational enterprise is accordingly to to be conceived as an arena for strategic rather than communicative action. Exploring the difference between both kinds of action, Habermas describes it as a question of 'the pretheoretical knowledge of competent speakers, who can themselves distinguish situations in which they are causally exerting an influence upon others, from those in which they are coming to an understanding with them'.5 Indeed any study of the history of Western educational institutions - from the period of Classical antiquity to the emergence of the 'postmodern' themes of recent decades - will supply only rare instances of an educational ethos characterized by efforts of teachers and learners to come to shared convictions in an unforced way. This is probably as true of the history of higher learning as it is of the history of primary and secondary schooling.

Now, curiously, the situation in which the noble lie is first suggested is itself one of communicative rather than of strategic action. More precisely, it is ostensibly so. In the middle books of the Republic we witness three partners in an exploratory dialogue, seeking to come to a shared conviction in an uncoerced, unconstrained way about the nature of justice and 
the means for its promotion in the polis. Plato places Socrates and two youthful partners, Glaucon and Adeimantus, in a situation where any idea or suggestion, no matter how far-fetched, can be ventured in the dialogue and its merits given serious and lengthy consideration. Apart from the outburst of Thrasymachus in Book I (who is clearly portrayed as a petulant contrast to the dialogue's main characters), the ethos of the dialogue unfolds for the reader as one of urbane reasonableness, and this tends to mask or to mitigate the coercive character of many of its main conclusions. But it is important to recognize that this reciprocal reasonableness among the partners is not an emergent characteristic of an actual speech situation: rather it is a literary atmosphere contrived by Plato to present his monological arguments in the most attractive light. In particular, the use of the dialogue form canvasses the impression that the conclusions reached express a common will - a will which has been enlightened by the communicative events of the dialogue. And on a more intractable issue, the casting of Socrates as the chief protagonist in the dialogue tends to locate the dialogue itself inseparably among the distinctive activities of the historical Socrates - activities which Plato had already done much to record for posterity and which were aimed at seeking knowledge collaboratively, as distinct from transmitting truths didactically. ${ }^{6}$

If we look more closely then at the kinds of action which characterized the philosophical efforts of Plato on the one hand and Socrates on the other, the educational significance of the distinction I am attempting to explore reveals itself more clearly. Let us begin with Plato, and introduce Socrates along the way. Apart from the general points already made, there are two particular recommendations in the Republic which are strikingly at odds with what we know of the communicative practice of Socrates. The first of these concerns how teaching, as a human activity, is to be conceived. And here, the famous similes of the sun, the divided line and the cave are directly relevant, since they serve as dramatic devices to introduce Plato's metaphysical theory of truth, for which education will become the chief instrument:

Then what gives the object of knowledge their truth and the knower's mind the power of knowing is the form (idea) of the good. It is the cause of knowledge and truth and you will be right in thinking of it as being itself known, and yet as being something other than, and even more splendid than, knowledge and truth, splendid though they are. $^{7}$

What the lengthy and rigorous enterprise of teaching and learning must achieve, in Plato's scheme, is the turning around of the 'eye of the soul' from its saturation in a morass of culturally induced ignorance, to ascend to a vision of the eternal and changeless good, and to become purified 
and transformed by this ascent. Plato, as we know, clearly lays out a curriculum through which the ascent is to be pursued by those chosen for it by the rulers. But on the kind of action required for the pursuit itself, Plato is uncharacteristically terse. He makes his Socrates say: 'Then this turning around of the mind might itself be made the subject of a techne $\bar{e}$, which would effect the conversion as easily and effectively as possible'. ${ }^{8}$ The rationalist tenor of this remark contrasts strongly with one of the more characteristic and memorable claims of Socrates, reported for instance in the Protagoras. In that dialogue, after listening to the sweeping declarations of Protagoras to be able to teach virtue, Socrates opens a sustained debate with the reply 'I did not think that this was something that could be taught? 9

The second of the recommendations which utters oddly from the mouth of the Socrates of the later books of the Republic, concerns the requirements necessary for the commencement of work on the construction of a polis characterized by justice. Describing the rulers of the envisaged polis as 'philosophic artists', Plato makes his Socrates assert:

The first thing our artists must do - and it's not easy - is to wipe the slate of human society and of human habits clean. For our philosophic artists differ at once from all others in being unwilling to start work on an individual or a city, or draw out laws, until they are given, or have made themselves, a clean canvas. ${ }^{10}$

If this recommendation were to be taken as a literal prescription for action, then the kind of action necessary would be inescapably authoritarian, and relentlessly so. Even then, it is unlikely that its success (or effectiveness) would be anything more than partial. The historical evidence of conquests, persecutions and attempted 'exterminations' shows this clearly enough. Whether these recommendations - and the other controversial provisions of the Republic - were intended as a warrant for an authoritarian and closed society (as, e.g., Popper claims), or whether the entire book must itself be read as one grand utopian dialectical myth (as, e.g., Gadamer maintains), there is still little in Plato's Republic, or indeed in his later provisions for education in his Laws, which calls our attention in a primary way to forms of practical action other than law-making, custodianship, censorship, self-denial, the acknowledgement and contemplation of eternal truths, the discharge of duties of office and obedience to authority.

The contrived character of the ethos of reasonableness in the Republic becomes more evident when we recognize a shift in the style of authorship at a crucial stage. From the point in the text where the question of education is first introduced (Book II, 376c), the contributions of Glaucon and Adeimantus lose the exploratory and critical character they had up to then. Control of the action from here onwards becomes increasingly 
concentrated in the hands of Plato's Socrates, and Glaucon and Adeimantus are called on to do little more than keep up the appearance of dialogue by successive acknowledgements of the compelling force of the arguments of the senior partner. These developments are punctuated by strategically placed questions of Plato's making, which enable that senior partner to elucidate his author's metaphysics at considerable length. The fact that Plato does not henceforth allow a form of action where such elucidation would be seriously contested at any controversial or questionable points by either of the two junior partners, reveals that the these very points are not open, as they would be in a genuinely Socratic dialogue. Plato himself is accordingly revealed as someone who is a committed custodian of a truth of an absolute and changeless character, which if not quite certainty, is virtually so. ${ }^{11}$ The superior character of changeless truth therefore takes precedence for Plato over any truths which might be disclosed by the interplay of viewpoints in a Socratic enquiry: truths, that is, of an emergent, provisional, self-critical character. The kind of ethical commitment revealed by this latter kind of enquiry is one which gives to a jointly undertaken pursuit of truth, a place of special importance among human activities. It suggests that we uncover something of our best selves in the disciplined conduct of self-critical dialogue. There is more than a hint here of an ontological claim - a claim that Gadamer was explicitly to express in the words 'the dialogue that we are'12 - a claim moreover which remains present but implicit, behind the procedural character of Habermas' theory of communicative action. By contrast, a conception of education which gives priority to the transmission of changeless truths closes off any scope for taking up such a suggestion, or for entertaining the ontological claim and its practical consequences.

The history of education in the European and Western world - until the Enlightenment and long afterwards - provides a replete testimony to the recurrent victory of Platonist conceptions of truth over the Socratic championship of joint enquiry. This history bears witness to the casting of teaching and learning as a conformity with the precepts of authority. It bears witness also to the eclipse of a form of educational action where the identity of individuals and groups would be allowed a judicious latitude and scope in the interplay with the voices of tradition. The enterprise of learning, in other words, becomes more a colonized institution than a pursuit enjoying a qualified degree of sovereignty. Of course this history is well documented and widely known, but while the denial of sovereignty may in the past be associated with the strategic interests of an authoritarian church or state, in modern Western democracies the colonizing impulse is usually more implicit, but often scarcely less real. It has now largely passed to other hands, but to see this more clearly, together with its import, we need first to examine at closer range what actually befalls us when teaching and learning take place. 


\section{The Lifeworlds of Learning}

The argument in this section is set out in thirteen numbered paragraphs, each one advancing the argument a further step. In unfolding the argument, I am keen to proceed from an account of what actually befalls us, over and above our wanting and doing, to an account of what might most appropriately happen to us, or what what kind of educational action we might most defensibly engage in, when we consciously bring our wanting and doing into play. As I move from the first to the second of these phases I will be attempting to put Habermas' formulation of the principle of universalization to work in practice: attempting, that is, to explore the nature of what it commits us to, and to make an appraisal of this. So before embarking on my thirteen steps, let me quote Habermas' formulation of this principle:

(Thus) every valid norm has to fulfill the following condition: (U) All affected can accept the consequences and the side effects [which] its general observance can be anticipated to have for the satisfaction of everyone's interests (and these consequences are preferred to those of known alternative possibilities for regulation). ${ }^{13}$

For the sake of completeness it is worth adding Habermas's shorter maxim:

'valid norms must deserve recognition by all concerned ${ }^{14}$

\section{The Argument}

1 In the formal language of schooling we are thoroughly familiar with locutions such as 'the transmission of skills and attitudes', 'the passing on of cultural heritage', 'the imparting of knowledge'. Yet such familiar utterances, despite their currency, are far from doing justice to actual practice. When placed under scrutiny they can properly be seen as little more than clichés, (i.e. 'truisms' which tell only half of the story). Moreover, by beclouding the more significant part of the story, such truisms can induce a habitual failure of discernment among those who accommodate them uncritically in their educational outlooks.

2 Teaching is never a one-way activity of 'transmission', 'imparting', or 'passing on', no matter how purged such activity seeks to be of perlocutionary intent, or more particularly, of harbouring proprietorial designs on the sensibilities of the young. Teaching, rather, always brings about learning of some kind, even if the learner learns little more than to dislike the teacher or perhaps learns to become more adroit in resisting what the teacher tries to teach. So teaching and learning constitute at a minimum - a joint activity: an experience shared, from different 
cultural standpoints, by teacher and students. More precisely, this experience can be described as an unfolding interplay: between the ever-emergent abilities and sensibilities of students on the one hand, and, on the other, the voice which addresses these abilities and sensibilities through the presentations and enactments of the teacher. But what identifies the legitimate intent of such presentations? And what does voice mean here?

3 Clearly, what addresses the students through the presentations of the teacher makes an appeal of some kind to their attentions, their efforts, and indeed their commitments. How can such appeals be justified? Is it by calling attention to a test or examination which draws ever nearer from the distance? Such justifications as this may of course have practical effects on sizeable numbers of students, but they will have little on others and will be resented by many who may already see themselves among the ranks of the 'also-rans' or even 'non-runners'. In any case, the doubtful merits of this kind of justification side-step the central issue, and give pride of place to something other than the authenticity of the voice which seeks to be addressed to the students.

4 The authenticity of that voice, and of its appeal, whether it be the voice of history, Irish, science, maths, religion, art, or whatever, might perhaps best be illustrated by describing the activity of teaching and learning not just as an ever-emergent interplay, but as an interplay which is at the same time a special kind of communicative action: namely, courtship, or wooing. At first sight this may seem bold to the point of audacity, and of course it requires clarification. So, to begin with, it must be emphasized that courtship here is meant as no mere metaphor. It seeks rather to describe the kind of cultural interplay which the experience of teaching and learning actually is - including, as we shall see, those turbulent cases where the teacher's approaches are rebuffed or even ridiculed by the students. To describe the experience of teaching and learning as a courtship moreover, is to highlight just those vital dimensions of teaching which Plato obscured, and also to make available to us what are, perhaps, the most secure grounds for withstanding the charge of indoctrination.

5 In the interplay of cultural influence - no less than in the conduct of affairs of the heart - we can identify different kinds of courtship. We can recognize the kind of courtship which declares its intentions with honesty, which pursues them accordingly, which recoils from the forcing of a suit, which has the courage to face difficulties as they arise, which prizes both frankness and the dignity of privacy, which seeks to evade the ruts of mere habit, and which draws its special character from the delights and disappointments, the frustrations and 
surprises of mutual discovery, or shared disclosure. In short, we recognize something of a categorical sense of care here in one person's basic attitude to the other. We are well aware however that there is another, perhaps more common, kind of courtship, where considerations of a more questionable kind are to the fore: where the arts of dissembling and seduction are harboured and nurtured, where perlocutionary devices are ingeniously honed and deployed, where the characteristics of the first kind of courtship are at best secondary to the securing of the prize, or perhaps more accurately, the imagined prize. Of course courtship can frequently alternate between the different kinds, but I am keen to identify those features of courtship which would render it more a form of communicative than of strategic action.

6 In the kind of cultural courtship which - I am arguing - embodies the heart of education as a legitimate form of intercourse, the authentic voice of the subject (e.g. history) speaks only in so far as the teacher's enactment succeeds in casting that voice in an engaging, yet faithful idiom: an idiom which addresses the sensibilities of the students in an inviting, challenging, self-critical and sincere manner. In other words, the idiom is adapted and the manner is enacted to call forth a questioning, but open-minded response from the particular students being addressed. It is important to recall here what was said above about teaching and learning being an interplay rather than a transmission, so some kind of response is going to be forthcoming anyway, even if its true character cannot be discerned on the surface.

7 Now, if I teach history, or Irish, or science, or religion, or any other subject which has gained a place on the school curriculum, it is a defensible course of action (or normatively right) that 1 should encourage my students to see that I believe that the subject I'm teaching has something rich and enduring to offer. It is similarly defensible moreover that I should wish my students to share something of my own enthusiasm for the subject: that my occupational commitment as a teacher should express itself - taking the four examples mentioned - in encouraging them individually and collectively to discover something of the historian in themselves, or something of linguistic aptitude and appreciation in themselves, or something of the scientist in themselves, or something of their own religious sensibilities. None of this is to deny that it may take inspired pains, a discerning and tough faith, and sterling reserves of equity and forebearance on the teacher's part to unearth that 'something'. Nor is it to deny that the 'something' may initially look quite puny even when it is unearthed. Such unearthing invariably marks an advance in shared understanding however: an event of emancipation of the student (and the teacher) from a previously inhibiting state. It enables the student 
to understand something more of her own particular promise, her own aptitudes and limitations; to take a genuine step in the gradual appropriation of her own identity.

8 The picture is quite different however, and gives legitimate grounds for disquiet, if, as a history teacher, I seek to inculcate in the students a personal allegiance of my own to an officially sanctioned, or otherwise tendentious version of the past; if as a science teacher, I seek to silence any side of the argument on safe sources of energy; if, as a teacher of Irish, I insinuate the view that this language confers the badge of cultural or racial superiority; if, as a teacher of religion, I treat matters of faith as if they were matters of fact; if, in any instance of teaching, my approach presumes some proprietorial claim on the sensibilities of the students. Unless the disavowal of such a claim becomes an imperative of professional discipline in teaching, the interplay of influence between teachers and pupils may become rapidly, even irrevocably, disfigured. The lifeworlds of learning may thus become inured to institutionalized forms of colonization: often ones which may be happily blind to their own partisan character.

9 The point to emphasize from these explorations is that there are virtues of teaching which are candidates for universal validity, as distinct from being sectional or factional virtues. These virtues disclose themselves as procedural requirements in any serious effort to give practical effect to the principal of universalization in the contexts of teaching and learning. But this also means - contra Habermas - that the principle of universalization is more than a formal, procedural principle, and that efforts to give effect to it reveal inescapable connections with substantive ethical orientations. Recalling the argument of the last four paragraphs then, such virtues can now be seen to include:

(a) a circumspect honesty in declaring one's own intentions as a teacher;

(b) patience and persistence, which are judicious rather than importunate;

(c) the courage and moral energy to tackle obstacles and challenges;

(d) frankness, coupled with respect for each student's privacy and dignity;

(e) an originality which resists the ruts of habit and returns anew to the address of the subjects which are the teacher's abiding point of contact with the students;

(f) a judicious faith in students, even in unpromising or inhospitable circumstances;

(g) a disavowal of proprietorial designs, coupled with a constructive sense of self-criticism; 
(h) a categorical sense of care for students, including an unfailing commitment to equity and to high expectations.

This last requirement, a categorical sense of care, is evident in one way or another in all variants of what Habermas calls 'cognitivist ethics', including his own 'discourse ethics'. Consider for instance Habermas' formulation: 'The moral principle is so conceived as to exclude as invalid any norm that could not meet with the qualified assent of all who are or might be affected by it'. ${ }^{15}$ In our efforts to give effect to this principle in practice however, what is excluded serves to place in sharper focus what must be included: for instance, not just procedures, but procedural requirements which have the character of substantive virtues, such as the list just outlined. These virtues of teaching are human practices moreover, rather than merely attitudes, or commendable sentiments. They are still not the same however as the skills (technai) of teaching (e.g. classroom management skills), though they can dramatically transform how the skills of teaching are exercised. The virtues of teaching are concerned, first and foremost, with the releasement and enablement of students. This does not mean any kind of releasement or enablement, but rather the venture of uncovering the nature and scope of the student's ownmost promise. The specific, yet universal, character of these virtues of teaching make them worthy candidates for the occupational commitments of teachers as professionals. Such virtues are thus to be distinguished from teachers' personal convictions in matters of ethics, politics, religion, etc., although they may well be in harmony with, or draw sustenance from, the latter.

10 The virtues of teaching just mentioned nurture a commitment to the end-in-view of the kind of communicative action we are currently exploring. That end-in-view can now be described as the actual bringing about in some sustained measure (not just the facilitation) of a genuine engagement between the emergent potentials of the students and the authentic voices of the differing subjects which seek to address these potentials. It is important to emphasize that it is not the bringing about of conformity; nor is it acquiescence in a code of dogmatic canons, whether in science, religion, politics, literature, history, or any other subject. The success intended here is in crucial respects procedural, though it also orients the emergent moral climate in certain directions rather than others. I'll return to this question of ethos in a moment, and again at the end, but at this point we also need to note that the exercise of the virtues of teaching may require a teacher to intervene decisively at times and exercise authority in a firm manner. Such intervention makes the interplay between teacher and learner even more asymmetrical than usual, but this should not 
be confused with the use of power for arbitrary purposes (though it could degenerate into that). Rather its justification would be that of earnestly attempting to restore an orientation towards a shared understanding, whether of the nature of a difficulty in mathematics, of the nature of a conflict in history, or of the nature of a contentious moral issue.

11 In all practical instances where rules of procedure are being applied, a distinctive ethos arises unavoidably from such application. Where rules have been decided on high and enforced with strict punitive measures, the ethos is likely to be one of compliance, coupled perhaps with an undercurrent of resistance, of minor or maybe major proportions. By contrast, where the rules and their application are a practical working out of the kinds of virtues we have been considering, a distinctive ethos arises quite naturally, as distinct from something imposed. Or to use Habermas' phrase, 'communicative action provides the medium for the reproduction of lifeworlds'. ${ }^{16}$ (I take this to mean the reconstitution or reconstruction of the lifeworlds of learning of individual pupils, with a view to bringing about qualitative changes, rather than the reproduction of any status quo.) In this latter kind of ethos, the growing commitment of pupils and teacher to such rules helps to build personal identity around an unforced spirit of community. Such an ethos greatly helps the teacher moreover to present her subject (or subjects) in a manner best adapted to her students. She is accordingly enabled to provide a robust defence of her subjects, and to have her own understanding of them challenged to further efforts by the students' questions and comments. This is the fruitful interplay of a cultural courtship in action.

12 Teaching and learning have been described here not as different experiences, but as an experience shared, from different perspectives, by teachers and students. Accordingly, the virtues of teaching, outlined first in paragraph 9 above, can be seen to be paralleled by virtues of learning, which the kind of ethos just described seeks to sustain among the students. Chief among such virtues of learning, which can now be listed, are the following:

(a) a commitment to effort in the pursuit of fluency;

(b) tolerance and cooperation among students, in relation to each other's attempts;

(c) method and growing discernment in their efforts to understand;

(d) acknowledgement of the claims of balance in the exercise of critical judgement;

(e) acknowledgement of the claims of equity in all aspects of teaching and learning; 
(f) receptive openness by students to what is decently addressed to them;

(g) readiness to ask questions or raise critical queries;

(h) willingness to take responsibility for their own learning.

13 When taken together, the virtues of teaching and learning not only describe how educational practice might look in a state of relative sovereignty, they also provide defensible criteria for teachers to make an appraisal of their own occupational commitments and of their own professional practice. This is not to suggest that they are a catalogue of qualities for sainthood. It is important to stress that, as criteria, they emerge from practice, they seek to be universal in character, and therefore seek to serve as the basis for a universally defensible ethic for teachers. Of course the freedom to elaborate and to practice such an ethic is often curtailed by a host of institutional constraints, or precluded by legal instruments, or indeed undermined by inhospitable philosophical outlooks which gain more than a tentative footing in influential quarters. It is to this cluster of inhospitality that I want to turn in the next section of the paper.

\section{The Dialogue that we Aren't}

Towards the close of his book The Postmodern Condition, Jean François Lyotard suggests that the evolution of social interaction is taking the following course in those collectivities which he variously describes as 'post-industrial societies', 'computerized societies', or 'postmodern cultures':

The temporary contract is in practice supplanting permanent institutions in the professional, emotional, sexual, cultural, family and international domains, as well as in political affairs. ${ }^{17}$

Lyotard describes the world of 'post-industrial' society as one where the necessity to justify actions by reference to some universally defensible criteria has been largely superseded by the pragmatic demand to perform effectively in the various spheres of action (or 'language games' as he calls them) which make up social intercourse. The scope of his analysis covers social, political and cultural life in the widest sense, but he focuses in particular on two main categories of 'language games'. On the one hand, he gives a key importance to scientific knowledge and its efficient production, and on the other, he identifies 'narrative knowledge', which includes standards of acceptability and performance for such domains as the ethical, the evaluative-aesthetic and the socio-political more generally. ${ }^{18}$ It is important to distinguish between what Lyotard calls ordinary narratives and what he calls 'grand narratives', or 'metanarratives'. Ordinary narrative he describes as the kind of knowledge that 
'does not give priority to the question of its own legitimation' and that 'certifies itself in the pragmatics of its own transmission without having recourse to argumentation and proof'. ${ }^{19}$ Of particular importance for Lyotard in this connection are the assumptions - moral, political, and aesthetic - which are characteristic of particular cultures and which are largely taken for granted in the 'language games that combine to form the social bond ${ }^{20}$ in those cultures. On the part played by narratives in such language games he remarks:

Narratives ... determine criteria of competence and/or illustrate how they are to be applied. They thus define what has the right to be said and done in the culture in question, and since they are themselves a part of that culture, they are legitimated by the simple fact that they do what they do. ${ }^{21}$

Lyotard believes that the quest for anything more than this kind of immediate legitimation - a quest which is a distinguishing mark of critical philosophy from Socrates to the present - is a superfluous and even an ominous one. Accordingly, he claims that his second category of narrative - what he calls the 'grand narratives' or 'metanarratives' of Western philosophy - has lost its credibility in a postmodern culture. Such 'metanarratives' would include all philosophical efforts which seek to identify universal rather than immediate criteria for any field of human endeavour, or which presuppose anything like a worthy end for humankind as a whole. Examples of prominent 'metanarratives' which Lyotard cites are 'the dialectics of Spirit, the hermeneutics of meaning, the emancipation of the rational or working subject, or the creation of wealth'. ${ }^{22}$ In this single citation, Lyotard waves a dismissive hand over a very wide range of religious, philosophical and political conceptions of humankind, and of its prospects for freedom - conceptions which have been central to Western philosophy. Without naming anybody, the philosophical endeavours of Hegel, Kant, Marx, Heidegger, and Adam Smith, not to mention the classical Greek philosophers, are curtly discarded. Rather more pointedly, the same judgement extends to prominent living philosophers whose works are far from having lost credibility: Habermas, Gadamer and Ricoeur. In an essay included as an appendix to the English version of The Postmodern Condition, Lyotard identifies the work of Habermas as the chief target of his polemic. ${ }^{23}$ In a bold and memorable phrase in the Introduction to the book, Lyotard declares: 'I define postmodern as incredulity towards all metanarratives'. ${ }^{24} \mathrm{He}$ offers no justification (or 'legitimation') for this standpoint of incredulity, but simply asserts that it is both the product of progress in the sciences and is in turn presupposed by such progress. ${ }^{25}$

The summary nature of Lyotard's arguments and the unrestrained sweep of his conclusions make his analysis questionable on virtually all important points. Here, however, I shall concentrate on examining his comments 
on 'legitimation', with a view to making explicit what I believe to be an underlying incoherence in Lyotard's postmodernist standpoint. 'Narration', Lyotard argues, 'is the quintesessential form of customary knowledge', and he describes a number of features of such knowledge in order to show how ordinary narratives create and maintain the social bond in the particular cultures which embody them. These features include: the moral-heroic contents of popular stories, the rituals and routines of storytelling, the variety of culturally accepted patterns of behaviour which stem from a particular culture's narratives; the apprenticeships which must be served before a member of a culture can be accepted as a 'sender' as distinct from an 'addressee' of a narrative. ${ }^{26}$ But Lyotard now jumps to two strange conclusions from this analysis of the functions served by ordinary narratives. The first of these conclusions - which he acknowledges goes 'against all expectations', is that 'a collectivity that takes narrative as a key form of competence has no need to remember its past'. ${ }^{27}$ The second conclusion, which is related to the first, is his declaration that the ordinary narratives of particular cultures are legitimated simply by their degree of effectiveness in the culture in question, or in his own words: 'legitimated by the simple fact that they do what they do' ${ }^{28} \mathrm{~A}$ few pages later, Lyotard's distaste for any further forms of legitimation than those provided by uncritical criteria of effectiveness ('performativity') makes him add to these conclusions the declaration that the search for such further legitimation is a special form of Western cultural imperialism. ${ }^{29}$

Lyotard's conclusions on the forgetting of the past, and on the selfsufficient legitimation provided by ordinary narratives, might conceivably have application in a culture which remained closed to all external and critical influences. But this is a condition which is scarcely attainable in any culture which falls under his own description as a 'computerized', or 'postmodern' society. The very pluralism of such societies means that narratives which have been traditionally accepted in their cultural heritages are being continually contested, not least by the proliferation of critical and revisionist forms of scholarship and by literary journalistic critiques of culture which have become an everyday occurrence. The pervasive and frequently acrimonious character of such pluralism moreover gives point and urgency to disciplined efforts to identify legitimate forms of communicative action which would combine tolerance with diversity the universal with the particular: for instance efforts such as those of Habermas, Thomas McCarthy and Richard J. Bernstein..$^{30}$ Or we might also refer to efforts such as those of Gadamer and Ricoeur to identify new forms of solidarity, including the contribution which criticalhermeneutic reflections on experienced traditions might make to this quest. ${ }^{31} \mathrm{I}$ am keen to argue that contemporary philosophical efforts such as these bear witness in different degrees, and in somewhat different ways, to that vulnerable, committed, but communicatively open way of being 
human which Gadamer called the 'dialogure that we are'. I would like to add moreover that such witness has a crucial significance for education, including policy-makers and teachers. By contrast, any rejection of the aspiration towards universality closes the door on such dialogue and almost inescapably asserts a contrary orientation for human intercourse, most frequently one towards power, or coercion, or cultural superiority whether in traditional authoritarian dress or in the playful attire of postmodernism. It must be admitted however that this latter orientation, viz. the 'dialogue that we aren't', may be more alert than the 'dialogue that we are', to new moves in the dance of fashion in matters political, ethical and educational.

Yet the legitimizing of the practices of a particular culture - by uncritically drawing on the culture's own key narratives, or by furnishing denials of solidarity in attractive presentations - is clearly a precarious undertaking in modern (including 'postmodern') societies. Although less than impartial conceptions of the quest for truth frequently enjoyed a lasting place in the sun in the history of Western civilization, they also fell to memorable ridicule on occasion, or came to grief in the most dramatic way: for instance the example of Socrates' encounters with the Greek sophists, politicians and jurors, or Christ's encounters with the Jewish High Priests, or Luther's break with Roman tradition, or the Enlightenment and its extended critical legacy. Against Lyotard's postmodern incredulity it must be pointed out that historical instances such as these, together with an abundance of present-day examples, bear recurring witness to something which cannot be simply dismissed as a 'metanarrative' of philosophy: namely, to an experienced practical imperative among politically alert peoples in all continents. This imperative is for more critical and more universal forms of legitimation than those of local tradition, or those of a tradition which has become a self-sufficient 'language game', uncritical of its own presuppositions and orientations. It is an emergent or incipient aspiration towards the 'dialogue that we are'.

The ontological presuppositions of Lyotard's argument now call for particular attention. They betoken a conception of human being where one is the effectiveness of one's present performance, or more precisely, where the status of one's being as a human is the effectiveness of one's moves in a competitive (agonistic) language game. What Lyotard describes as the 'tendency towards the temporary contract' in the various spheres of human intercourse, is a tendency which contrasts sharply with traditional conceptions of identity, commitment, responsibility, and defensible action - whether of conservative, radical or other ancestry. The enduring character of such traditional conceptions is discarded in favour of conceptions which highlight the tentative and episodic. One's life becomes, as it were, not so much an unwritten novel or autobiographical drama, with what MacIntyre describes as an unfolding narrative continuity from birth 
to death; rather it becomes more an unwritten anthology of short stories - transitory episodes which differ from the chapters of an autobiography in that the self who is the author of any one story is a temporary self. This would be a self with possibly radically different outlooks, aspirations and actions from the temporary selves who 'are' the author of any or all of the preceding and succeeding stories.

The picture here is not entirely unfamiliar. At the level of educational practice, we have become increasingly familiar in recent years with features such as the following (and here I confine myself to four developments):

(a) short-term contracts which continue to gain ground in replacing permanent appointments for teachers and lecturers;

(b) 'performance indicators' which virtually equate educational quality with effectiveness of output, whether of published articles or certificated students;

(c) modularization of curricula, which enables the various disciplines of learning to be more easily packaged as commodities for consumer choice and for effective 'delivery' in a time span of a semester or less.

(d) A conception of the university which seeks to relegate and even to displace the disinterested pursuit of learning, and its attendant requirement of a qualified academic sovereignty, in favour of the university as a strategic intellectual and technological resource: a resource, that is, for the more effective servicing of the demands of society, conceived as as a social, as well as an economic market.

The image of the market captures not only the shifting nature of supply and demand, a feature which has been traditional in markets throughout history. More significantly, it captures an emergent social reality of our times with startling force. It is well known that the markets of technologically advanced countries, if they are to meet their own targets for effectiveness, must rely on the widescale stimulation of desires, cultivation of appetites, and manipulation of tastes. This is accomplished through such devices as aggressive advertising, recurrent trend-setting, and through incessant efforts to destabilize and colonize the ever-emergent and frequently vulnerable sense of personal identity. Now if we extend these manipulative devices from the markets of commerce and economics into the ethical, cultural, and artistic aspects of communication, that is into human intercourse itself conceived as a social market, we begin to see more clearly the features of what I have called 'the dialogue that we aren't', and how this coalesces with the Nietzschean provenance of most of what Lyotard describes in The Postmodern Condition.

Lyotard's description of the postmodern condition is not of course an isolated philosophical tract on our times. It has echoes in Richard Rorty's insistence on the 'incommensurability' of different discourses and in 
Derrida's embrace of différance. ${ }^{32}$ Rorty's description of himself as a 'postmodern, bourgeois liberal' is intended to remind his readers that his overt partiality towards the traditional liberal ideals of bourgeois culture is not paralleled by any commitment to the traditional philosophical underpinnings of these ideals. Indeed his hostility towards epistemology and towards any kind of search for philosophical 'foundations' has strong parallels with Lyotard's 'incredulity towards all metanarratives'. Rorty's conception of 'edifying philosophy' as a kind of continually renewed 'redescribing' or 'remaking' of ourselves ${ }^{33}$ also calls to mind the episodic, or transitory character of 'language games' in Lyotard's postmodernism. This connection is further strengthened when we recognize that Rorty's 'redescribing' is made possible only by his decisive break with any necessity to ground philosophy in presuppositions which might be candidates for universal defensibility. Moreover he views such continual 'redescribing' as 'the most important thing we can do', and attempts to appropriate Gadamer's educational concept of Bildung to this most anti-hermeneutic of projects. ${ }^{34}$ Finally, Rorty's evident celebration of such 'remaking' and 'redescribing' is reminiscent of Lyotard's emphasis on the avant garde: or more precisely on 'the increase of being and the jubilation which result from the invention of new rules of the game, be it pictorial, artistic or any other' ${ }^{35}$

Certain influential features of Derrida's 'deconstruction' also add to this picture of 'the dialogue that we aren't'. Consider for instance the practical import of his championship of différance, with its attendant ambiguities and ambivalences - particularly where an educational engagement with a cultural and intellectual heritage must be got under way in some sustained manner, and for entire school-going populations. Consider further the import of his attachment to the play of undecidability over any enduring practical commitment. Consider finally his apparently endless deferral of any definitive emergence of moral identity and also the continuing unreadiness which follows from this to accept any but the most minimal responsibility in practice for one's self, one's beliefs and attitudes, and one's conduct. In referring here to influential features of Derrida's 'deconstruction' however, I don't wish to focus just on the clamour of the deconstruction industry in literary and philosophical criticism. In particular I don't wish to overlook the possibility that there may be in the ambivalent and ambiguous play of differance, something which might enable a genuine dis-mantling or dis-robing of the most urbanely attired prejudices: something which might allow what has been thought and said in the historical conversations of humankind to be experienced with moral inklings which reach beyond the assurances sought by most traditions of moral enquiry. ${ }^{36}$ What kind of communicative or educational action might follow from this possibility is however a problematic issue. So in short, on one reading, Derrida's work can be seen as a key feature of the inhospitable cluster I have been exploring. On another reading, his work 
points in the opposite direction to that of postmodernists like Lyotard and Rorty - a direction which occasionally recalls the thought-provoking Socratic combination of commitment and uncertainty.

\section{Conclusions: the Autonomy of Moral Theory?}

I would like to make some concluding remarks now on how I think Habermas' work stands in relation to the picture I have been sketching of 'the dialogue that we aren't'. In the closing section of his essay 'Morality and Ethical Life', ${ }^{37}$ Habermas draws the attention of his readers to the limitations of the discourse ethics which he has championed. One of the questions he raises here is 'whether it is reasonable to hope that the insights of a universalist morality are susceptible to translation into practice' ${ }^{38}$ Acknowledging that what he has to say on this question may come as a disappointment, he sees it as incumbent on moral enquiry to explain and ground the moral point of view in some universalist ethic. And he sees this as an essentially theoretical task.

But isn't it inescapably the case that the insights of a universalist morality arise in the first instance from practice itself, or from the lifeworlds of those who hold these insights? In this connection, I believe there is a keen hermeneutic insight in MacIntyre's arguments on the secularization of morality by the Enlightenment - particularly his claim that judgements issuing from the ostensibly autonomous sphere of morality (and he has Kant in mind in particular) are in fact 'linguistic survivals from the practices of classical theism which have lost the context provided by these practices' ${ }^{39}$ That is to say, the effective history of classical theism lives on in a secularized form in the dispositions and the arguments of the modern Kantian moralist. Or, more precisely, the morality proposed by the Kantian moralist wants to preserve and refine some essentials of the substantive orientation of a traditional theistic morality, but to replace its particularist character and its teleological programme with a universal formula. This kind of insight seems to be supported by Habermas' own arguments on 'lifeworld' knowledge, or 'pre-reflexive', 'background' knowledge in The Theory of Communicative Action, where he describes it as having the three following remarkable features:

It is an implicit knowledge that cannot be represented in a finite number of propositions; it is a holistically structured knowledge, the basic elements of which intrinsically define one another; and it is a knowledge that does not stand at our disposition, inasmuch as we cannot make it conscious and place it in doubt as we please. ${ }^{40}$

What this amounts to is that the demarcation between concrete ethical life on the one hand - which is invariably pervaded by the quality of our 
upbringing and everyday experience - and, on the other hand, the claims of rational critique and moral theory, is a demarcation which distorts our understanding of human understanding itself. The exploration of teaching and learning in action, carried out in part two of this paper, bears this out. So to conclude, as Habermas does in the following passage, seems to me to be to take a wrong turn:

What moral theory can and should be trusted to do, is to clarify the universal core of our moral intuitions and thereby to refute value scepticism. What it cannot do is make any kind of substantive contribution. ${ }^{41}$

This passage, with its heavy emphasis on a circumscribed rational domain for theory, seems to assert that there can be such a thing as unprejudiced moral theory as such: an autonomous court of purely procedural enlightenment, unaffected by or unflavoured by the moral and practical presuppositions of everyday experience, or if you like, lifeworld experience. By contrast, I would maintain that in so far as there can be such a court of reason, it is necessarily a court of rationality in action, so its procedures always owe something to the background perspectives and orientations of its participants, and its autonomy in this sense is never more than partial. Its inspirations and judgements moreover remain in some inescapable sense indebted to, or encumbered by substantive prejudgements of a moral/practical character. In summary, the procedures of communicative action invariably embody virtues of a practical kind, and these reveal that communicative action itself proceeds from selfcritical reflection within one or more normatively oriented traditions, rather than from anything like a rationally autonomous moral theory. I'd like to finish then by calling attention to a remark of Paul Ricoeur's at the close of his essay 'Science and Ideology', where he declares:

For nothing is more necessary today than to renounce the arrogance of critique and to carry on with patience the endless work of distancing and renewing our historical substance. ${ }^{42}$

I don't think Ricoeur is suggesting that critique is necessarily arrogant, but I would like to shift the emphasis of his remarks by saying that the 'dialogue that we are', and the educational practices which are its strength and sustenance, finds its most promising possibilities in an alert hermeneutics which remains both critical and self-critical. By contrast, such a dialogue is shipwrecked by the games of postmodernism and is drawn on a wrong path by the claims of autonomous theory.

St Patrick's College, Maynooth, Co. Kildare, Ireland 


\section{Notes}

1 An earlier version of this paper was presented to the Spring Conference of the Irish Philosophical Society in Kilkenny, on 17th April 1994, in response to a Call for Papers on themes related to the work of Jürgen Habermas.

2 Plato, Republic, 389b-c.

3 Ibid., 415a-b.

4 Ibid., $459 c-60$ e.

5 Jürgen Habermas, The Theory of Communicative Action, Vol. 1, trans Thomas McCarthy (Boston: Beacon Press, 1985), p. 286.

6 The criticisms of Plato's arguments which follow from this point onwards in the text should not obscure the sense of our indebetedness to Plato, which I am keen to acknowledge here. Without the Dialogues of Plato, our knowledge of Socrates would be much impoverished, as it would have to rely mainly on the accounts of Xenophon and Aristophanes. Kierkegaard has made an illuminating study of the sources of our knowledge of Socrates in his early work The Concept of Irony (1841), trans Lee M. Capel (Bloomington: Indiana University Press, 1965, 1982).

7 Republic, $508 \mathrm{e}$.

8 Ibid., 518d.

9 Protagoras, 319b, 320b.

10 Republic, 501a.

11 Ibid., 533a.

12 Hans-Georg Gadamer, Wahrheit und Methode, 4 Aufl. (Tübingen: J.C.B. Mohr Paul Siebeck, 1975), p. 360: 'Wir suchen von dem Gespräch aus, das wir sind, dem Dunkel der Sprache nahezukommen'. Truth and Method; 2nd German edn, trans Garrett Barden and John Cumming (London: Sheed \& Ward, 1975), p. 340.

13 Jürgen Habermas, 'Discourse Ethics', in his Moral Consciousness and Communicative Action, trans Christian Lenhardt and Shierry Weber Nicholsen (Cambridge: Polity Press in assoc. with Blackwell Publishers, Oxford, 1990), p. 65.

14 Ibid.

15 'Discourse Ethics', op. cit. note 13, p. 63.

16 The Theory of Communicative Action, op. cit. note 5, p. 377.

17 Jean François Lyotard, The Postmodern Condition: A Report on Knowledge, trans from French edn (1979) Geoff Bennington and Brian Massumi (Manchester: Manchester University Press, 1984, 1992), p. 66.

18 Ibid., pp. 18-19.

19 Ibid., p. 27.

20 Ibid., p. 25.

21 Ibid., p. 23.

22 Ibid., p. xxiii.

23 'Answering the Question: What is Postmodernism', in The Postmodern Condition, op. cit. note 17, p. 72.

24 The Postmodern Condition, op. cit. note 17, p. xxiv.

25 Ibid.

26 Ibid., pp. 19-21.

27 Ibid., p. 22.

28 Ibid., p. 23.

29 Ibid., p. 27.

30 See e.g. Thomas McCarthy Ideals and Illusions: On Reconstruction and Deconstruction in Contemporary Critical Theory (Cambridge, Mass.: MIT 
Press, 1991). See also Richard J. Bernstein Beyond Objectivity and Relativism (Oxford: Basil Blackwell, 1983) and The New Constellation: The EthicalPolitical Horizons of Modernity/Postmodernity (Cambridge: Polity Press, in assoc. with Basil Blackwell Ltd, Oxford, 1991).

31 On this issue see Gadamer Reason in the Age of Science, trans Frederick G. Lawrence (Cambridge Mass.: MIT Press, 1982) and also Paul Ricoeur Hermeneutics and the Human Sciences, ed. and trans John B. Thompson (Cambridge: Cambridge University Press, 1981).

32 See Richard Rorty Philosophy and the Mirror of Nature (Oxford: Basil Blackwell Ltd, 1980), and also his essay 'Postmodernist Bourgeois Liberalism' in Hermeneutics and Praxis, Robert Hollinger ed.(Notre Dame: University of Notre Dame Press, 1985), pp. 214-221. See also Jacques Derrida Margins of Philosophy (1972), trans Alan Bass (Chicago: University of Chicago Press, 1982).

33 See Ch VIII of Philosophy and the Mirror of Nature, op. cit. note 32.

34 Ibid., pp. 358-9.

35 The Postmodern Condition, op. cit. note 17, p. 80.

36 John D. Caputo provides this kind of reading of Derrida's work in his book Radical Hermeneutics: Repetition, Deconstruction, and the Hermeneutic Project (Bloomington \& Indianapolis: Indiana University Press, 1987).

37 'Morality and Ethical Life: Does Hegel's Critique of Kant apply to Discourse Ethics', in Moral Consciousness and Communicative Action, op. cit. note 13, pp. 195-215.

38 Ibid., p. 210.

39 Alasdair MacIntyre, After Virtue: A Study in Moral Theory, 2nd edn (London: Duckworth, 1985), p. 60.

40 The Theory of Communicative Action, p. 336.

41 'Morality and Ethical Life' op. cit. note 5, p. 211.

42 Paul Ricoeur, 'Science and Ideology', in Hermeneutics and the Human Sciences, op. cit. note 31, p. 246. 